\title{
Performance Management: How the Swedish Administration of Transportation for the Disabled Succeeded. A Case Study of Transportation Service for the Disabled, the Municipality of Gothenburg
}

\author{
Iwona Sobis ${ }^{1}$, Offolome Guepie Victorien Okouma ${ }^{2}$
}

\begin{abstract}
Management by objectives (known also as performance management) has been perceived as a promising steering method in the public sector since the beginning of the 1990s (Smith 1993, 1995; Kravchuk and Schack 1996; Ballantine et al. 1998; Ferreira and Otley 2009 Verbeeten 2008). However, working out operative goals of public organizations seem to be a challenge because major objectives formulated by politicians are often unclear and difficult to measure (Rombach 1991; Lundquist 1992; Gray and Jenkins 1995; Lapsley 1999). It is known that public organizations' services like school, health care, welfare care, collective transportation, infrastructure and cultural services are usually unprofitable. The Transportation Service for the Disabled in the Municipality of Gothenburg is an exception. It fulfilled most objectives and achieved a profit of 7,890,000 SEK for 2013, while the planned one was scheduled at 5,000,000 SEK. Maybe performance management used as the steering model caused that result but the criticism targeting management by objectives suggests that this method hardly can explain such a positive result. Brorström et al. (2005) and Grönlund and Modell (2006) argue that in Sweden management by objectives is usually used in combination with other control models. The purpose of this study is to describe and explain why the Transportation Service for the Disabled succeeded in 2013 and to provide practitioners nationally and internationally with some pragmatic ideas how to improve the efficiency and effectiveness of public services. We ask three sub-questions: How were the operative goals created within

1 Associate Professor, School of Public Administration, Gothenburg University, Gothenburg, Sweden.

2 Alumnus of Master Program, School of Public Administration, Gothenburg University, Gothenburg, Sweden.
\end{abstract}


the Transportation Service for the Disabled? How were the operative goals followed up? What can be learned from this case study? The research is based on the analysis of state regulations, internal policy documents, reports and interviews with key respondents. The study shows that the performance management systems (PMS) in combination with a new organizational culture based on SMART solutions, mutual cooperation among staff, with local politicians and other stakeholders resulted in the increase of efficiency and even partly effectiveness. However, these findings deserve further research if there are other public administrations that succeeded because of using PMS and friendly organizational culture.

\section{Keywords:}

Management by objectives, performance-management systems, public sector, efficiency, effectiveness, SMART, organizational culture, cooperation.

\section{Introduction}

Since the 1990s, the expansion of New Public Management (NPM) has been observed across the world, when the public sector was in crisis. Then, management by objectives, also known as performance management, was perceived as a promising steering method just in times of crisis. From the literature, it appears that this method operates in parallel with other steering models. In Sweden, indeed, there is a mix of steering models (Brorström et al. 2005; Grönlund and Modell 2006). The growing efficiency of the Swedish public sector is associated with this perspective of NPM that has focus on decentralization and internal control (Almqvist 2006). Currently, public organizations have extensive autonomy to steer and control their own activities. However, similarly to traditional economy steering NPM makes a distinction between those who govern and those who carry out the day-to-day work, which means that local politicians have great influence on local governance by making decisions on major objectives to be achieved by public administration. To work out operative goals of civil servants is a real challenge because major objectives formulated by politicians are often unclear and difficult to measure. Some scholars perceive management by objectives as a panacea to solve the public sector's problems (Smith 1993, 1995; Kravchuk and Schack 1996; Ballantine et al. 1998; Ferreira and Otley 2009 Verbeeten 2008). Others argue the opposite: management by objectives by no means can contribute to increasing efficiency and effectiveness because it is inadequate for the public sector (Rombach 1991; Lundquist 1992: Gray and Jenkins 1995; Johanson and Skoog 2007). Public service is not working for profit but for people, for citizens to provide them with necessary services, e.g. school, health care, welfare care, collective transportation, infrastructure and cultural services. These services are not profitable, to the contrary they cost the state and municipalities and are financed by a taxation system. Independently of the criticism directed towards management by objectives, concepts like performance management, management 
by objectives, performance management system, growing efficiency and effectiveness, deregulation became guidelines for everyday work within the public sector. The clue is that objectives have to be set, followed up and measured.

In Sweden, politicians started to talk about management by objectives in the late 1980s. The concept became more popular when a new municipal law came into force in 1991. According to it, municipalities decide on fundamental issues such as objectives and guidelines for the operations, budget, taxes and other economic issues. They also take care of the organization of boards, activity forms, annual reporting and discharge. Municipal government manages the municipality according to city council's objectives, directives and guidelines. Moreover, municipal government has the supervision over councils and corporations' activities (see: Kommunallagen (1991:900), kapitel 3,9\$). A policy document from the Municipality of Gothenburg (2008) tells us:

Governance is based on a city council, which sets out the vision and goals in the annual budget. The total target image is broken down into intermediate targets at each level. From councils, companies and administrations to schools, swimming pools, museums and offices. Then the goals are followed up, and they are reported back, e.g., from a preschool to a district, to a city council ... A purpose of evaluation and follow-up is that public administration should take advantage of its resources and deliver services with good quality (Så här styrs staden 2008, 7).

According to this document, management and evaluation are divided into five aspects: (1) objectives and budget, (2) measurement/evaluation, (3) analysis and reporting, (4) development/improvement and (5) dialogue and feedback. In this article, we focus on the Transportation Service for the Disabled in the Municipality of Gothenburg in Sweden, which, similarly to other public services, is not perceived as a profitably activity, but this organization is interesting because based on its Annual Report it appears that this administration not only fulfilled most major objectives but also reached a profit of 7,890,000 SEK for 2013, while the planned one was scheduled at 5,000,000 SEK. Thus, the criticism targeting management by objectives within the literature may not be relevant. We wonder: What has caused the Transportation Service for the Disabled to prove profitable and successful in reaching goals, while many other public administrations faced financial problems and hardly were satisfied with the fulfilment of goals?

The purpose of this study is to describe and explain why the Transportation Service for the Disabled succeeded. The additional aim is to provide practitioners nationally and internationally with some pragmatic ideas how to improve the efficiency and effectiveness of public services. We seek answers to three sub-questions: How were the operative goals created within the Transportation Service for the Disabled? How were the operative goals followed up? What can be learned from this case study? 
We think that performance management is the dominant steering model within the Transportation Service for the Disabled in the Municipality of Gothenburg. Studying this phenomenon, we believe that it would be possible to track the changes in local governance that could positively impact performance management.

After the introduction in Chapter 2, we present a theoretical reference framework on local governance and management by objectives. In Chapter 3 , we present our methodology. Chapter 4 opens with the presentation of empirical data. Firstly, the institutional context is presented in which the Transportation Service for the Disabled acts. Secondly, the focus is on the political objectives for the whole municipality and their translation into the operative goals within the Transportation Service for the Disabled and their achievement. The presentation of this organization's structure concludes the chapter. Chapter 5 presents the results of the research. In Chapter 6, when answering the research questions, we discuss the findings and draw conclusions from the whole study.

\section{Theoretical angles}

Below, we present theoretical insights dealing with local governance and management by objectives in order to grasp the studied phenomenon with the theoretical concepts when analyzing and interpreting collected data.

\subsection{Local governance}

Local governance, which is a broader concept than local government includes collective perceptions and collective actions at the local level. It encompasses formal hierarchies, institutions, brings in citizens, networks, community organizations in creating and delivering local public services (Shah and Shah 2006, 2). According to Bovaird and Löffler $(2002,10)$ these elements constitute the major criteria of shaping new local governance and its local environment in this millennium and guarantee well-being within local communities. This model is influential in the Nordic countries having interest in cooperating with public and private organizations and cooperating in various forms of networks and partnership. Denters and Rose (2005, 513) assert that local authorities have always been closer to citizen than to regional, national or international levels of government, which Bovaird and Löffler (2002) call "operationalizing of good local governance" (18). They also suggest that local authorities "apply a multiple stakeholder framework and transcend organizational borders" in order to "involve all important local stakeholders in the assessment by taking into account their perceptions of how well governance issues are dealt with in their local area" (18). Good local governance means more than good local government in the sense that it implies learning and partnership through "public consultation, public involvement, user involvement and citizen engagement in the affairs of the local authority" (17-18). 


\subsection{Management by objectives}

The concept of management by objectives known also as management by result was used for the first time by Peter Drucker in 1954, when he described the traditional process of governance, in which managers and employees work out an organization's objectives together, and they agree about the ways to achieve them. Four decades later, it was associated with NPM spreading the new steering method known as performance management and performance measurement. The concept of objective plays a central role in the theory and is associated with an organization's efficiency (Smith 1993, 1995; Grönlund and Modell 2006). According to, e.g., Smith (1993, 1995); Kravchuk and Schack (1996); Ballantine et al. (1998); Ferreira and Otley (2005); Verbeeten (2008), politicians make a decision about major objectives for self-governing community while civil servants execute them. Because the concept of objective is unclear so far, the concept of management by objectives is also unclear. Scholars share the opinion that political major objectives must be translated and adapted into an organization's needs. In practice this means that major political objectives are broken down into smaller targets, i.e. into specific operational goals, and the last ones have to be measured. However, Rombach (1991) tells us that diverse interest groups formulate various objectives according to their own interest, and consequently political major objectives for a municipality or for a specific public administration have little to do with public administration's operative goals. This happens because politicians lack know-how skills. They hardly can explain to public servants their vision, objectives and strategies to achieve them. Hence, the major objectives are uncertain, and civil servants feel uncertain about what they are expected to achieve. Three years later, Johansson and Johansson (1994) tell us the opposite: a hierarchical order in the public sector is possible. It is enough that major objectives are broken down into specific targets for each unit of an organization, then goals become operationalized into concrete activities for civil servants. In this way "the chain of management by objectives" is created. Verbeeten (2008) and Brorström et al. (2005) share the opinion that operative goals fulfil four functions: (1) clearly formulated goals motivate employees to perform them, (2) an organization gets legitimacy in the outside world by making clear to citizens what goals the organization wants to achieve and how taxpayers' money is used, (3) the organization's operative goals serve as criteria for the evaluation of performance and for the "learning process", and finally (4) the organization's operative goals form a basis for the organization's system of reward and punishment that can contribute to increasing or decreasing efficiency and effectiveness. The literature shows that with time, the understanding for management by objectives has crystallized, and it has been widely used in the public sector. Moreover, benchmarking has supported performance management. However, performance measurement understood in terms of an organization's efficiency and effectiveness is still problematic. 


\subsubsection{Performance measurement}

Evaluations and follow-up play important functions in the public sector. Hence, quantitative measures of a financial character were used in a traditional control system to achieve a balance in performance management, but already Drucker (1955) observed that the measurement of objectives should not be limited only to economic results. Four decades later, Kaplan and Norton (1996) created Balanced Scorecard (BSC) - the new governance model that measured: (1) financial indicators, (2) customer perspective, (3) production processes and (4) the organization's ability to learn and grow. BSC was based on goals anchored in organization's vision and objectives. The authors say: "If you can't measure it, you can't manage it" (1996, 14). Halachmi $(2005,5)$ asserts that BSC seeks to overcome common weaknesses of performance management and tries to introduce a measurement of the organization's outcomes. However, the use of BSC varies from organization to organization due to how this model has been interpreted. In Sweden, many public organizations introduced the employee perspective at the expense of the organization's ability to learn and grow, but the last one was widely discussed in organizations' annual reports as the conclusion drawn from the measurement of all BSC dimensions (see Hällstén and Tengblad 2006).

MacPherson (2001) has presented two types of measurement: the measurement of efficiency (short-term), i.e. output (results), and the measurement of effectiveness (long-term), i.e. outcomes, performance drivers. He argues that key indicators should measure both output and outcomes in order to anticipate future events. Scholars like, e.g., Lemieux-Charles et al. (2003); Modell (2004); Carlin (2004) show that organizations are looking for measurement that can reflect the quality of provided services, but there is still a lack of an adequate measurement of outcome. Zineldin (2006) asserts it is an "impossible mission" (10). Boyne and Gould-Williams (2003) argue that the diversity of key indicators negatively affects evaluations. Ehrenberg and Stupak (1994); MacPherson (2001); Stevens et al. (2006); Peng et al. (2007); van de Walle (2008) share the opinion that it is extremely difficult to formulate an organization's operative goals and find relevant indicators to measure them. Vakkuri and Meklin (2003) tell us that the problem with performance management depends on how data are collected, processed, analyzed and interpreted before making a decision about further development. Evans (2004); Carlin (2004); Goddard (2010); Verbeeten (2008) put an emphasis on how measurement results are communicated. This communication is difficult because civil servants often do not have enough time to ensure that reported data is reliable for decision-making. Ouchi (1977) suggests that the implementation of a management control system is necessary. Then, organizations can use three types of control: (1) control of output (result), (2) control of action (behaviour) and (3) control of clan (personal/culture). The controls of output deal with evaluation and rewards/punishments of individual respective groups. The controls of action aim at an estimation of performance, if 
it is useful or harmful for the organization. Clan controls are about the control of one's own and others' behaviour. Verbeeten (2008) asserts that the most useful controls of output take place "when objectives are unambiguous" (429), but in publicsector organizations goals are usually ambiguous and have conflicting values. Thus, controls play an important role; for politicians because they get information about changes in their environment; for managers because they inform what should be changed or developed within organization; for citizens because they are informed about how their money was spent. Controls contribute to a learning process to improve performance management. According to Wang and Berman (2000, 405ff), performance measurement is possible in practice but firstly, it must be decided what is measured. Secondly, key indicators have to be identified. Thirdly, measurement results should be communicated in a proper way that civil servants learn of it. Thus, the organization should decide hard metrics (quantitative measures) for economic performance - output - and soft metrics (qualitative measures) for outcomes. Traditional economic measurement of output should be linked to the measurement of outcomes to have a better balance and a complete measurement system in the organization. Without the active involvement of central authorities into performance measurement, major objectives are not evaluated in a correct way (424ff). A similar spirit can be traded in Lindgren (2008,9), who makes distinctions between evaluation and follow-up. She compares evaluation to a monster. Evaluation is usually carried out by external consultants or researchers and is understood as the umbrella concept to critically examine the organization's performance by gathering information in a systematic way to make some comparisons with other organizations. Follow-up instead has an internal character; it is an ongoing activity conducted in agreement with some procedures to examine how an organization develops in one or more respects. Otley (1999) and Ferreira and Otley $(2009,43)$ have formulated twelve important questions when conducting follow-up. Those questions reveal the main idea behind the control system. Broadbent and Laughlin $(2009,285 f)$ created a model for evaluation that is based on the previous research conducted by Ferreira and Otley (2009). 
Figure 1

A model of Performance Management System (PMS)

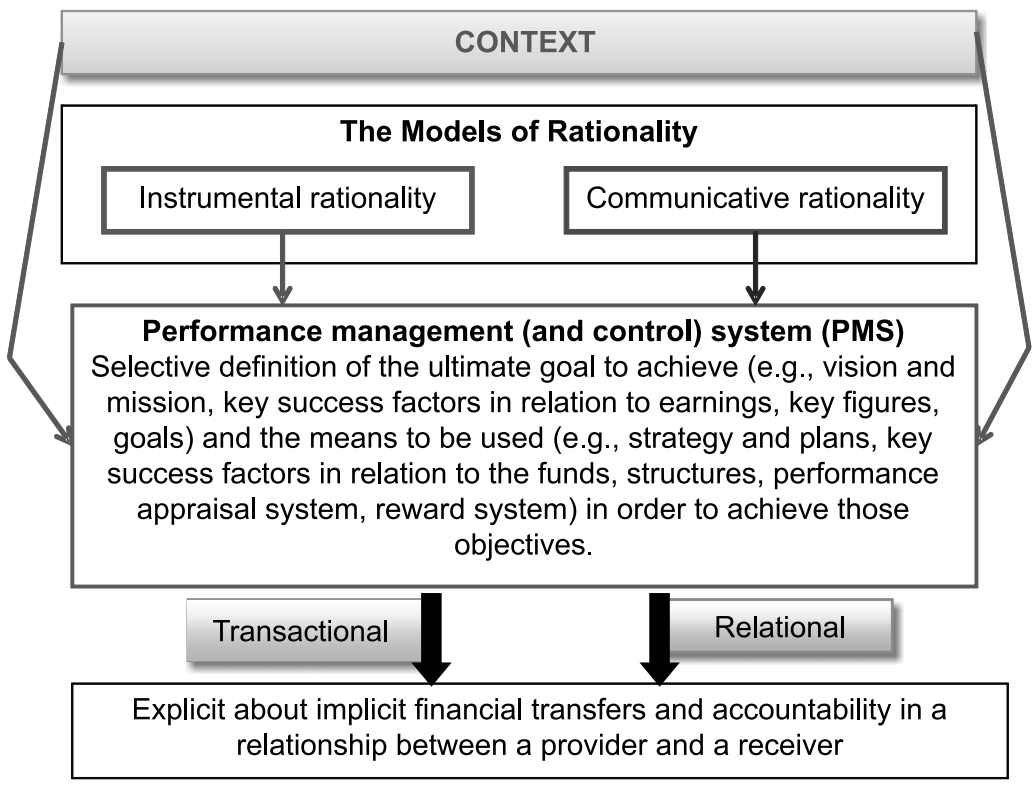

Sources: Broadbent and Laughlin (2009, p. 290)

Figure 1 presents this model. According to the model of the Performance Management System (PMS), the organization's external and internal environments constitute a context in which an organization is acting. It decides about potential opportunities and challenges when the organization needs to make a choice whether or not to respond to these challenges. The contextual presumptions are deeply anchored in the organization's history. Broadbent and Laughlin (2009) but also Ferreira and Otley $(2009,290)$ share the opinion that some questions have to be asked, especially the questions about the issues presented in the box Performance management (and control) system (PMS). At the bottom of Figure 1, the new element of the model is presented, which works as an intermediate filter reporting explicitly about implicit financial transfers and accountability in a relationship between provider and receiver. It informs about the organization's aspirations and performance.

\subsubsection{Benchmarking}

Benchmarking became a new steering method when public-sector organizations were under enormous pressure from internal and external interest groups and when performance results proved to be very difficult to measure in practice. This means that an organization evaluates output and outcomes and compares them to best practices in other organizations. These comparisons allow working out plans to 
improve one's own performance (Bovaird and Löfler 2002). It proved necessary because previous research showed that the distinction between means and results made performance measurement not effective (see, e.g., Rombach 1991; Gray and Jenkins 1995; Lapsley 1999; Hyndman and Eden 2000, 2001). Thus, the relationship between the definition of efficiency (output) and the definition of effectiveness (outcomes) is very important for a better understanding of performance management.

According to Grönlund and Modell (2006) efficiency is about the use of resources and the number of products or services worked out (output). Efficiency is based on goals and measures used in various measuring moments on a resource conversion chain, and therefore it involves resource utilization and productivity. However, the use of resources is somewhat opposite to productivity. It refers only to the input of different types of resource and does not take into account achievements resulting from various activities. Productivity is normally defined in terms of a ratio between performance and input of resource (e.g. revenue costs or number of manufactured products/man hours). Thus, efficiency is a short-term approach to business: public organizations still have to plan their activities in the framework of an allocated budget. Effectiveness (outcomes) concerns long-term effects of an organization's activities. It is about the quality of performance and the social benefit, i.e. operative achievements and the organization's way to respond to social needs and th eneeds of various stakeholders. Effectiveness is understood in terms of goal achievement that has public value. It is very difficult to create a relevant measurement for this purpose. The existing measures depend on random variations rather than a clearly observable causal relationship between outputs and outcomes.

We believe that the theoretical angles presented above allow us to trace the practical work within the Transportation Service for the Disabled to explain what caused the goal fulfilment of this public administration in 2013.

\section{Method}

This research is a case study based on the analysis of state, municipal regulations, public political documents, internal policy documents, the Annual Report 2013 from the Transportation Service for the Disabled as well as semistructured interviews conducted with key actors from this administration in the early autumn of 2014 .

The most important ones are: (1) Lag om kollektivtrafik (Act on Public Transport), SFS 2010:1065; (2) Lag om färdtjänsten (Act on Transport Service for the Disabled), SFS 1997:736; (3) Lag om riksfärdtjänsten (Act on National Mobility for the Disabled), SFS 1997:735), (4) Färdtjänstnämndens budget (Budget of Board of Special Transportation Services), 2013; (5) Politiska inriktningsmål (Policy orientation) 2013; (6) Yrkande (S, V, MP) Policy inriktningsmål 2013 (Claim (S, V, MP) Policy orientation, 2013); (7) Trafikförsörjningsprogram för färdtjänst och riks- 
färdtjänst (Traffic Maintenance Programs for Special Transportation and National Mobility) 2013-2015; (8) Färdtjänstnämnden: Årsrapport (Annual Report, Special Transportation), 2013; (9) Färdtjänstnämndens uppföljningsrapporter (Transportation service follow-up reports of the Board), 2013.

The interviews were conducted with: (1) the Director of the Transportation Service for the Disabled and six departmental managers for: (2) Travel Service, (3) Permission Department, (4) Administrative Support Department, (5) Traffic Department, (6) Communications Department, (7) Human Resources Department. The respondents were working within this administration from 7 to 22 years, and they had sufficient work experience to tell us about their working methods with the management by objectives.

The interview guide was divided in three themes:

(1) Respondents about management by objective and the design of operative goals for their administration; we asked some questions about the organization's vision, the way they created the operative goals for the organization and what strategies they had to achieve them.

(2) Respondents about the performance measurement for output and outcomes: we asked questions about the way they were converting the operative goals into the concrete key figures or indicators measuring the performance in terms of output and outcome. What was easy to measure, what was problematic to measure and why they thought so.

(3) Respondents about the achievement of goals: This thematic block was about the respondents' reflections about the practical implication of management by objectives for the achievement of goals.

The theories about local governance, performance management and theories on benchmarking became our glasses to look at the studied case, guiding us when asking questions. The model of the performance-management system created by Ferreira and Otley (2009) and developed by Broadbent and Laughlin $(2009,285 f)$ proved especially useful when interviewing. However, we did not follow the mentioned models slavishly. It served rather as the inspiration how the interviews could help us to get useful information and secure internal validity. In general, the questions for the respondents had to be tailored to the respondents' specific responsibilities and work experiences. To get a better understanding of performance management within the Transportation Service for the Disabled, we also asked follow-up questions due to the situation during the interviews.

On the request of the respondents, we sent the main set of semi-structured interview questions to them a week before interviewing, which could affect the research results. The interviews were conducted at the respondents' workplace. On average an interview took about 30-60 minutes. All interviews were recorded and 
later transcribed verbatim. When quoting, we used the respondents' formal positions. In public administration, it is very difficult to promise an anonymous participation in the research. This research did not touch any sensitive issues that could affect the respondents' integrity or violate their ethical code. To the contrary, the studied case represents rather good practice, maybe a pattern to follow for other public organizations.

During the analysis and interpretation of the empirical data, we were looking for sense-making and for evidence allowing us to answer the research questions and draw conclusions from the research.

\section{The institutional context for the activities of the Transportation Service for the Disabled}

According to the Public Transport Act (SFS 2010:1065), the Act on Transport Service for the Disabled (SFS 1997:736) and the Act on National Mobility for the Disabled (SFS 1997:735), every county is responsible for special public transportation in the region addressed to the disabled. The Act on Transport Service for the Disabled (SFS 1997:736), 3\$ explains that such special transport services should be organized in each municipality and between municipalities (see: Law 2006:1114; SFS 1997:736). A municipality, after agreement, may transfer a principal responsibility for the special transportation service to a county or a region. Those municipalities that do not do that, have to take responsibility for such services themselves (Traffic Maintenance Programs for Special Transportation and National Mobility 2013-15, 3).

The Municipality of Gothenburg has run the transportation services for the disabled since 1967. The budget is the most important document. The municipal council's major objectives and guidelines for all activities within the municipality can be traced, including the special transportation services. Thus, the Board of Transportation Service for the Disabled owns the questions about budget, vision, political objectives, strategic lines to achieve goals and the directives for all activities within the municipality. In the document of Claims ( $S, V, M P)$, Policy Orientation $(2013,2)$, the emphasis is put on flexible transportation services for the disabled who cannot use the regular public transport. The flexible transportation services constitute a complementary value towards the general public transportation (Traffic Maintenance Programs for Special Transportation and National Mobility 2013-2015, 7). In the same document, one can find arguments that flexible transport services offer safe travel, good service, punctuality and high availability (8). Permission to use the special transportation service is provided to the persons who have some kind of disability and for whom it is difficult to travel on their own (Act on Transportation Service for the Disabled 1997:736). 


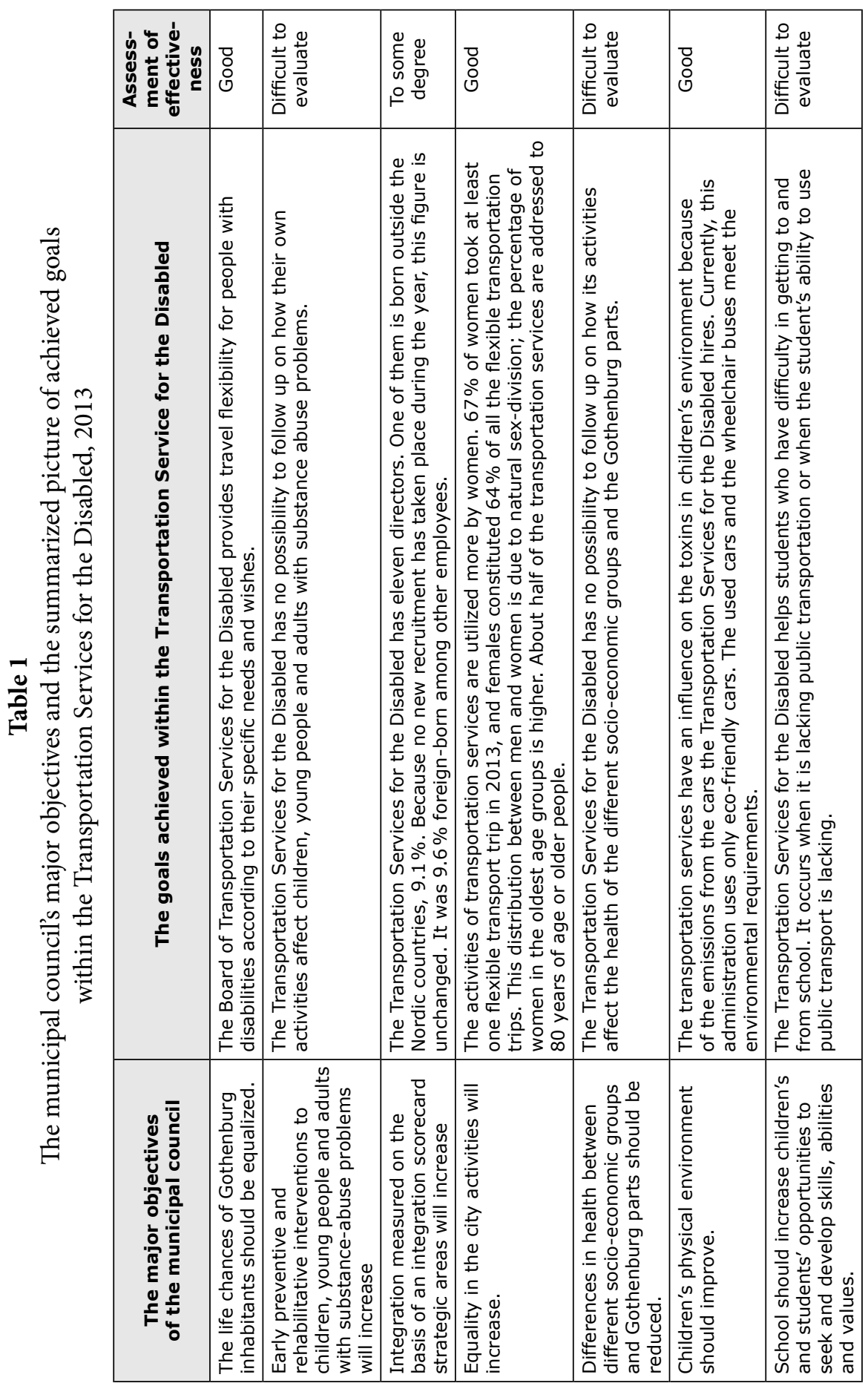




\begin{tabular}{|c|c|c|c|c|c|c|c|c|c|}
\hline 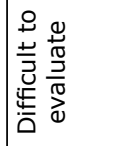 & 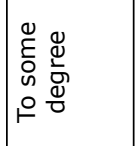 & 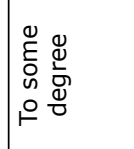 & $\begin{array}{l}\text { D } \\
\text { O } \\
\end{array}$ & $\begin{array}{l}\text { D } \\
0 \\
0\end{array}$ & 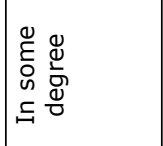 & $\begin{array}{l}\text { D } \\
\text { ठ } \\
\text { ( }\end{array}$ & $\begin{array}{l}\text { D } \\
0 \\
0\end{array}$ & ס & $\begin{array}{l}\text { D } \\
\text { ठ } \\
\end{array}$ \\
\hline 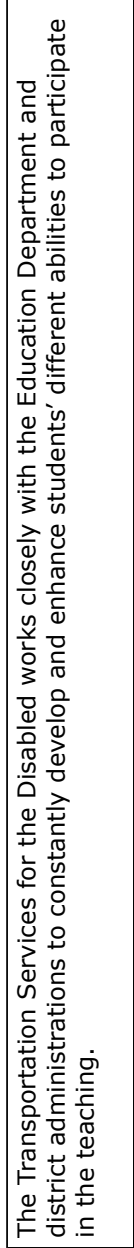 & 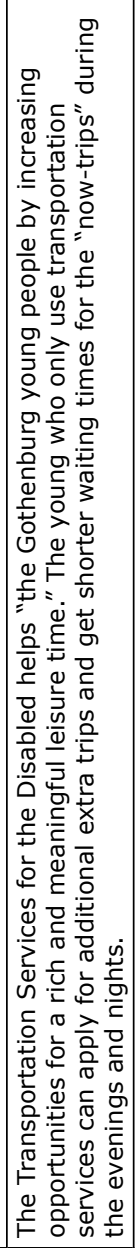 & 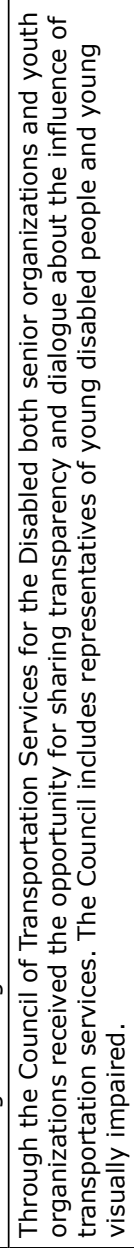 & 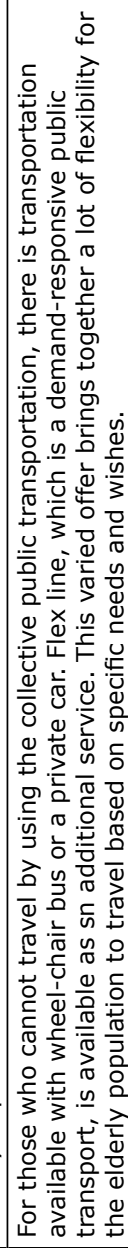 & 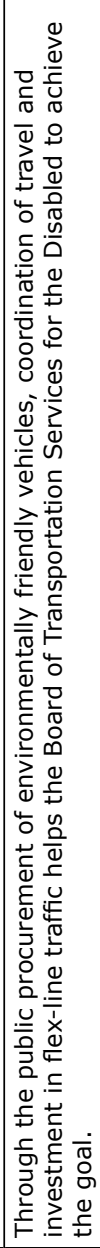 & 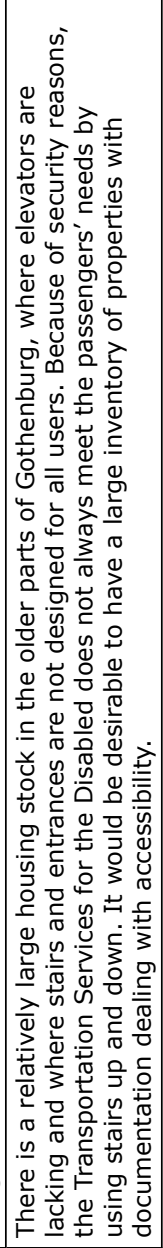 & 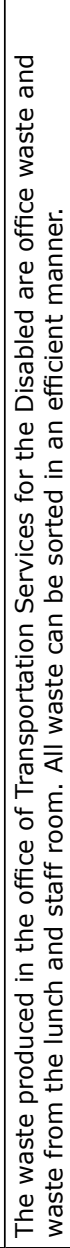 & 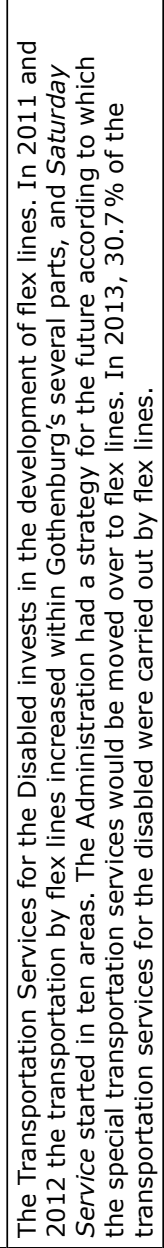 & 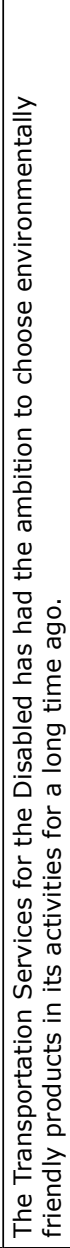 & 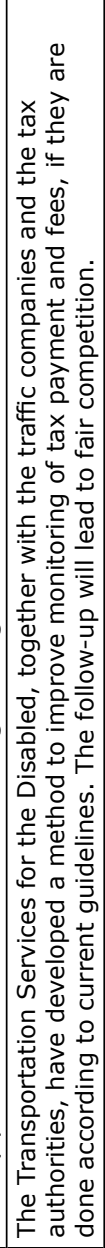 \\
\hline 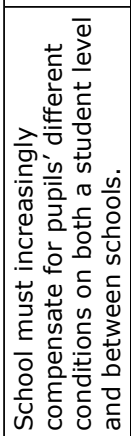 & 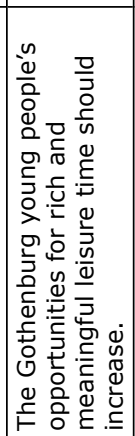 & 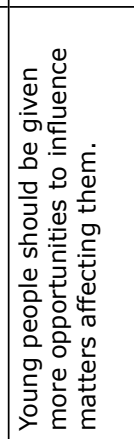 & 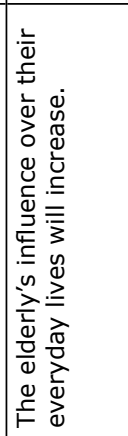 & 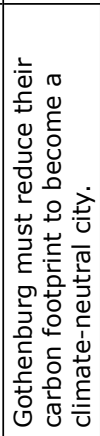 & 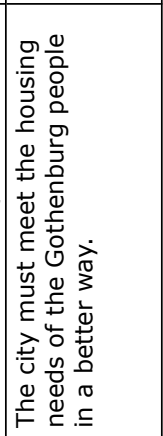 & 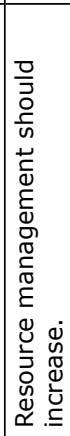 & 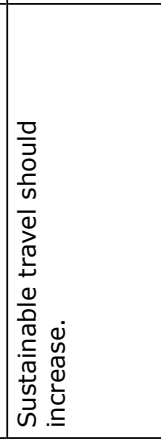 & 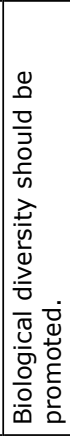 & 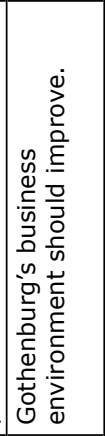 \\
\hline
\end{tabular}


There are five important steering perspectives: (1) users' needs should be indicative, (2) employees should have the opportunity for participation and engagement, (3) interactions with others within a whole-city-perspective are important, (4) environmental considerations should always weigh heavily, and (5) the budget must be kept (see: Claims (S, V, MP), Policy Orientation, 2013, 2; Traffic Maintenance Programs for Special Transportation and National Mobility 2013-2015, 7; Budget of the Board of Special Transportation Services, 2013, 5). The Board of Special Transportation Service for the Disabled is of the opinion that the reception, waiting and travel conditions for people with disabilities should be improved (Budget of the Board of Special Transportation Services, 2013, 16). The same document advocates the increased number of passengers among people with disability, giving them opportunities for an active life to increase their involvement in the democratic society (17). There is also an expectation that this public administration should ensure not only the city special transport service but also coordinate national services for the city's disabled when necessary (5). The Board should take into account the environment when conducting public procurements with carriers to increase the use of fossil-free fuels (14). Table 1, presented below, shows the municipal council's major objective for the Transportation Services for the Disabled within the Municipality of Gothenburg. It appears that not all major objectives were achieved in 2013 although the financial results of the Transportation Services for the Disabled showed a good result.

\subsection{The organizational structure of the Transportation Services for the Disabled}

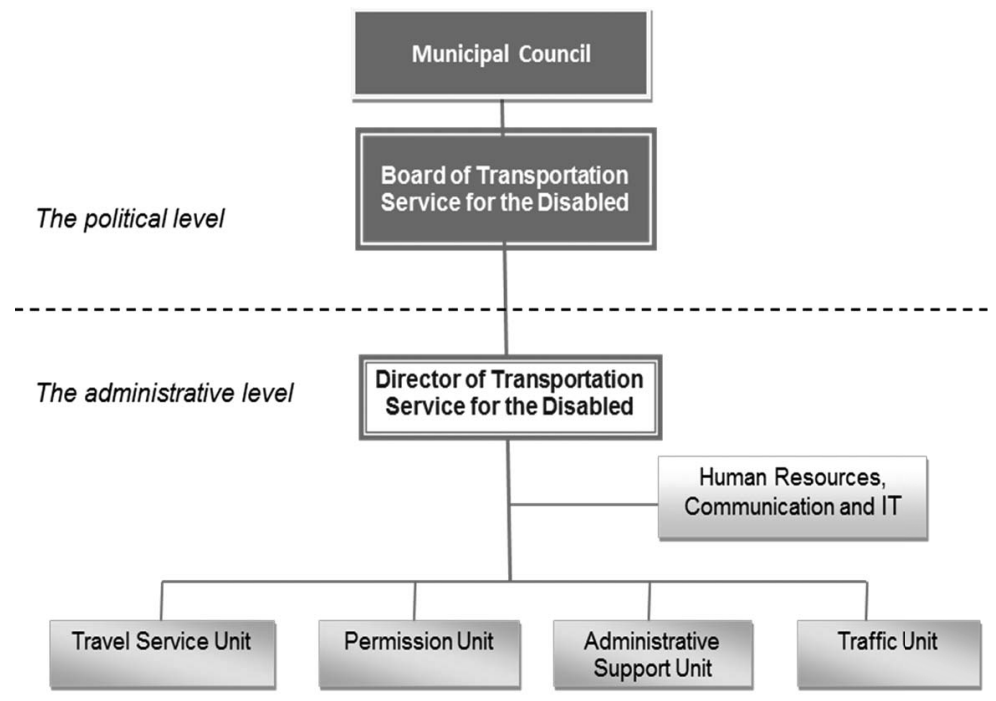

Sources: The Transportation Services for the Disabled: Organization andleadership (homepage updated. 2015-01-21) 
The Transportation Services for the Disabled are steered by the municipal council, i.e. the local politicians, who decide the major objectives and the budget for all activities of this administration.

The Travel Service Unit and the Permission Unit are perceived as the core activities within this administration because the first unit is responsible for taking orders for transportation services, flex lines and special orders, e.g. round-trips to school and home. This unit is also responsible for solving any problems that may occur on the roads and the reservation of national transportation services for the disabled. They have to answer questions concerning transportation for the disabled and take opinions about the provided services. The Permission Unit investigates and makes decision on permits allowing the use of transportation services for the disabled, and they are expected to follow the rules about equal treatment of users. The administrative support unit is responsible for financial management. The traffic unit buys cars and wheelchair buses, making sure that the environmental requirements are respected. There are also other units: human resources, communication and information technology (IT) having coordinators supporting management and employees' everyday work. The staff volume in 2013 was 131 employees, of which 103 were full-time employees, 4 part-time employees, 10 time-limited employees and 14 hourly paid employees (Färdtjänstnämnden 2013, 11).

The total population of Gothenburg in 2013 was about 532,222 citizens, of which 18,713 people used the transportation service for the disabled: $2 \%$ were young people $0-19$ years old, $10 \%$ constituted passengers $20-64$ years old, $24 \%$ were the elderly between 66-79 years old, and the largest group of passengers $-56 \%$ - constituted people in the age group of $80+$. In practice, not all the passengers with the permissions used the transportation services for the disabled. Women were over-represented among the passengers in the age of 66+ (Färdtjänstnämnden 2013, 16).

\section{Presentation of empirical data}

This chapter is divided into five topics explaining the way in which the operative goals were designed within the Transportation Services for the Disabled but also the way in which the civil servants were working in practice with performance measurement. When interviewing respondents and when reading the Annual Report 2013, we had the impression that the rudiments of Kaplan and Norton's BSC had been guiding civil servants' activities when creating the key figures or indicators necessary to follow-up the organization's performance. Hence, we partly behave according to this order we found in the Annual Report 2013 when presenting empirical data but the respondents' voices are in the focus, sometimes supplemented by data from the Annual Report 2013. 


\subsection{The respondents' general remarks about the creation of operative goals}

From the interviews it appears that the municipal council and the Board of Transportation Service for the Disabled were working in parallel with vision, operative goals and strategies for goals' achievement. According to the Director of Transportation Service for the Disabled, the objectives were on various levels:

The municipal council formulates the political objectives. They tell the Board of Transportation Service for the Disabled that they should work with these major objectives. Thus, the Board is working with the operative goals that we [Transportation Service for the Disabled] have to achieve in order to meet the political, strategic objectives. Then we prepare a business plan and a budget proposal for the Board. We usually have a theme day together with the Board of Transportation Service for the Disabled before we present our budget proposal. We make a plan on how we will work with the operative goals, and how we will translate the major political objectives into our activities. I think that it works fine (Director of Transportation Service for the Disabled).

The Administrative Support Manager adds that the vision of the Transportation Service for the Disabled is informal in its character, but it concerns good quality. The respondent explained: "People can phone us, be in touch, they get order for their journey". Passengers can share information how they experienced their travel: "In this way travellers have influence on the quality of our services ... in this way, we contribute to a better life for them" (the Administrative Support Manager). Thus, the quality of services is based on daily performance that is followed up.

The respondents were talking about external and internal factors that affected this administration's activities. The external indicators concerned the long-term financing of activities, and the Transportation Service for the Disabled could not control them. They could only affect the internal factors either directly by themselves or in co-operation with other partners.

The Transportation Service for the Disabled broke down the major political objectives into specific operational targets adapted for each unit, which essentially contributed to constructing the plan of activities. However, some goals went across different units. Thus, the civil servants co-worked in an ongoing dialogue. The Director explained: "we have goals for the different parts of the organization." The business plan remains a working chain, "in which processes include participation, clear roles and responsibilities." The same respondent expressed uncertainty "how far the goals can be broken down", but he had at hand a solution; the performance management has to be SMART, i.e. the goals should be Specific, Measurable, Agreed, Realistic and Time-decided. The plan for activities has to be anchored within the organization's vision, goals, strategy, but it also has to contain the quantitative 
and qualitative key indicators of performance measurement. These key numbers should facilitate the evaluation of efficiency and effectiveness, and they should be developed over time. The Permission Unit Manager believes that "it is very hard to live up to all expectations and goals." The Administrative Support Manager put an emphasis on communication that caused some problems.

\subsection{The operative goals seen from the passenger perspective}

The passenger perspective is about users' needs. According to the Annual Report 2013, two goals proved especially important: (1) passengers ought to have influence on the development of future trips - the good journey to a freer life; (2) the quality of the transportation service should be secured in terms of availability, punctuality, pleasant journey and pleasant treatment. This perspective concerned about 18,713 persons in 2013, who had the right to use the transportation services for disabled.

Most respondents, when talking about the operative goals seen from the passenger perspective, frequently used a normative tone in their statements; how things should go instead of how things went in practice. Thus, the respondents showed some kind of awareness about what activities deserved improvement within the administration. The Director explained that users had opportunities to influence the services through the Transportation Service Unit and through the Board of Transportation Service for the Disabled. The Board provided advice on disability issues. They cooperated with the representatives of users' organizations, consumers, politicians and management:

We have about 19,000 users who have the right to transportation service, and not everyone can be heard. However, those who are sitting in umbrella organizations can exert an influence ... In general, I think that our organization is very close to our travellers and politicians. I think that the users have a pretty big influence on our activities (the Director).

The general impression was that this organization really cared about users' needs. Each unit expressed it in its own way; the Travel Service Unit had "customers in focus". The aim was to provide them with good services that were of high availability. The Travel Service Manager and the Administrative Support Chief shared the opinion that their organization prepared full information about the special transportation services, including the special collective transport, addressed to the disabled. Passengers should also receive full and updated information in case of any changes. For the Permission Unit Manager, the most important goal was to guarantee legal security, to follow the rule of law:

We have to work in a procedural manner. We also have a lot of small targets, e.g. the civil servants make similar assessments regardless of which office worker makes the assessment. No one needs to wait for permission longer than a month ... We know 
that people with a certain type of disability often feel more vulnerable, that it can be a difference in provided services for men and for women, that some people expect a higher degree of transparency when making decisions. We understand it (The Permission Unit Manager).

This understanding led to civil servants using "a plain language" to avoid misunderstandings, which also affected behaviours, when civil servants explained the Permission Units' decisions to clients. Particularly vulnerable people needed a lot of assistance to understand the decision: "it affects our response" (The Permission Unit Manager).

For the Traffic Unit, the most important goals proved to have a sufficient number of vehicles to carry out regular trips, flex-line buses, wheelchair buses, wheelchair cars and passenger cars (taxis) and to secure "safe travels and happy travellers" (the Traffic Unit Manager). This respondent emphasized another important goal concerning the administration's cooperation with procured traffic companies: "the service providers selected by means of a public procurement get us as little complaints as possible. We want our trip to be on time and we want to reduce delays" (the Traffic Unit Manager). The IT Unit Manager ensured that the management system worked both for the customers and for the employees. The respondent stressed that information has to be constantly updated and clearly communicated. The only condition is that travellers and employee get the information they need. Moreover, they gathered information about what they had done in the business.

However, this positive picture presented by the respondents was somewhat contradicted by the Annual Report 2013 according to which travellers complained about the transportation services addressed to the disabled. The report showed that about 383 trips were wrongly booked in 2013 in comparison to 297 in 2012. On the other hand, little improvement was observed regarding the treatment of users; 101 complaints were made in 2013 compared to 123 complains in 2012. There were 1,005 complaints against carriers in the category of driver/location/services/vehicle in 2013 as opposed to 989 complaints in 2012. The Annual Report 2013 showed the clear deterioration during the period of 2011-2013 because the number of complaints was growing; in 2011 1,331 complaints were reported; 2,620 in 2012; and 3,054 in 2013 (21).

\subsection{The operative goals seen from the activity perspective}

This perspective focuses on action and endurance. A ruling motto for management was availability, security, safety, service and environmental concerns because these aspects were important for travellers. Hence, the most relevant operative goals proved to be the following: (1) following up carriers and making sure that good conditions were created for training opportunities for drivers, that vehicles were safe and that good environmental choice were made; (2) communi- 
cating and increasing carriers' awareness of the availability of transport services in Gothenburg as well as making carriers cooperate in a way that new vehicles in public transportation fulfilled the administrations requirements, (3) developing collaboration within and outside the organization, (4) contributing to working out an action plan, its implementation and follow-up with regard to Gothenburg being seen as an accessible city.

All respondents emphasized that the internal cooperation among various units and the external collaboration with traffic companies and other stakeholders was necessary. The big idea of cooperation was initiated by the municipal policy advocating for "whole-city-perspective" but at the same time, the internal cooperation affected the organization's efficiency and effectiveness because one unit's costs depended on another unit's activities. The Traffic Unit Manager expressed it as follow: "a civil servant at the Permission Unit gives a certain number of permissions, then the costs increase or decrease in the Traffic Unit. If the Traffic Unit does not collaborate with the Travel Service Unit, the risk of delays increases", which in consequence generates higher costs for the whole administration; thus such cooperation was very complex. The cooperation between the Transportation Service for the Disabled and the carriers was based on a signed agreement. Both partners had to comply with the agreement. The Travel Service Manager added: "what is most difficult and fun is that we are perceived as service performers" although Traffic Unit had bought the carriers and the carriers provided the transportation services for the disabled. The Travel Service Unit in fact managed the travels, i.e. they booked trips and ensured that those trips were performed in practice. If anything happened during a trip, they had to solve the problem. The staff of this department perceived their role to be "like a spider in the web; we have a central function; we get information from various sources and we have cooperation in most ways with all other units" (The Travel Service Unit Manager).

The Transportation Service for the Disabled was responsible for ensuring that the hired drivers participated in competence development, e.g. courses about human rights and LGBT questions (that stands for lesbian, gay, bisexual, and transgender issues). The management specified requirements for the procurement carriers to use environmentally friendly vehicles. According to the Transportation Service Board's Budget (2013) "environmental considerations always weigh heavily" (5), and the environmental requirements for vehicles and fuels play a central role within the Transportation Service Unit. They do not use gas-powered vehicles; instead they are using diesel emission vehicles with the insertion of non-fossil oil. Drivers are continuously trained in eco-driving (14). They also underline environmental requirements for public procurement of transport services; "all cars used in the operation must meet the requirements for the definition of environmental vehicles" (Traffic Maintenance Programs for Special Transportation and National Mobility, 2013-2015, 18). The respondents did not talk about this issue. This objective that 
the environmental perspective should be an integral part of the organization's everyday activities was taken for granted.

\subsection{The operative goals seen from the employee perspective}

From the employee perspective, the respondents repeatedly used these words: cooperation, engagement and participation. Employees were expected to cooperate with each other and with the outside world. The Director stressed that they must have good staff. On the one hand, the organization must support personnel, but on the other hand, they need personnel that can develop the organization. This perspective is about a "pleasant work place and well-being". All respondents mentioned how important it was to achieve goals. Most respondents have shared similar opinions about the value of good staff, e.g. the HR Manager said: "we must secure employment. It is the only way to be an attractive employer; then one can expect that work will be done in a professional way, that the organization's operative goals will be achieved". Right recruitment has a decisive importance, the same respondent added: "we must have the right people in the right place ... We have to ensure the development of skills ... It's about a safe working environment" but also about justice, gender equality, communicative leadership, good psychosocial and physical working conditions, participation and engagement, feeling that the staff has an influence on working activities. Moreover, the Travel Service Manager added "everyone should understand goals and be supposed to achieve them". The manager of the Traffic Unit said: "My team is definitely involved in the objectives. It is an active and very well educated group".

Despite the pleasant statements from all respondents, the Annual Report 2013 showed contradictory data again; the rate of sick leaves of 60 days increased from $36.9 \%$ in 2012 to $43.5 \%$ in 2013 . It was only $33.7 \%$ full-time employees who had the maximum of 4 sick days during a 12-months period in 2013 in comparison to 2012 when the corresponding share was $47.3 \%$ (11). Then, one wonders: how much attractive is the Transportation Service for the Disabled as a working place? Did employees really receive the necessary assistance from the organization when providing services?

\subsection{The operative goals seen from the economic perspective}

In the Färdtjänstnämndens budget of 2013, the Board of Transportation Service for the Disabled underlines that the main objective is to run the organization without deficit. The organization should have good cost control, carry out systematic followups and evaluations and observe the demographic changes (Färdtjänstnämndens budget of 2013, 6-7). The economic perspective is the most complex. On the one hand, it is about the budget itself, which constitutes the financial framework for all of the organization's activities. On the other hand, this perspective is about evaluation and follow-ups and the way the civil servants created key figures and indicators 
to measure the organization's efficiency and effectiveness. This perspective concerns financial planning, transport procurements with lower service costs, better logistics and investments that contribute to reducing operating costs, such as investments in IT and telephony.

Public servants were aware that the budget must be at least in balance, that money was the means to achieve the operative goals and to ensure higher quality of provided services. However, different units had different strategies to keep the budget in balance. When deviations occurred, discussions in groups took place to find remedial measures. The Director explained that a normal municipal budget is always a three-year plan while the budget of Transportation Service for the Disabled is planned on another two-four year. The organization is not living only on municipal grants. They also have the travellers' charges at their disposal and some possible fines from the transport agreements. However, it is a fact that they never know how much traffic will cost in the future. That is the reason why civil servants make different assessments and environmental analyses. They are working with the operative goals, strategies and plans on an ongoing basis. The Chief Financial Officer said:

We have a solid economic framework for each year. The goal is to try to implement activities that are as good as possible within the limits we have. Public services are often difficult to control. We cannot control the passengers' demand, as society develops, and so do the travel needs of people.... We have little money, but we cannot reduce peoples' travels, they will continue to ask for more trips. Then we struggle to find good solutions to still offer the trips that people demand, the trips which they are entitled to and perhaps at lower prices. Each trip is expensive, and we try to choose the most cost-effective solution each time. An alternative is that the disabled could use the custom scheduled-driven public transport (The Chief Financial Officer).

The Traffic Manager gave a similar report; budgeting was the most important. Thus, the management group had organized a conference every year which started the budget debate. During the conference a preliminary budget was created for the coming year:

It is clear that we must economize with money, but it is very much about where to put the focus right now. We had a bigger surplus during a time that our politicians wanted to invest in quality improvements. Thus, we carried out some quality improvements. However, in the long term, we know that the reality is changing. Socio-economic complexity, however, requires a certain amount of creativity. That is why we have a discussion when the budget is exceeded (The Chief of Traffic Unit). 
The Travel Service Manager pointed out that they kept the budget in balance although different factors had a negative impact on it. It was possible by two means; "either saving money or providing better service". The internal discussion within the administration and the external discussion with the politicians proved very important because the administration could present some saving propositions and discuss them further. Otherwise it was about focusing on service quality.

The Director argues that the organization's activities are planned in the frame of the budget, and all units have to follow up their own activities by the measurement of performance. For this purpose, the civil servants use qualitative and quantitative indicators to compare achieved results with the previous periods. The results are also compared to other municipalities' results in order to get a better understanding of the organization's current situation. The Director explains, "it is all about the measurement of relevant and necessary aspects" within the organization. Indicators are created if a civil servant finds secure key figures and if that servant has knowledge about the history of public administration, i.e. "how we've developed things. But, we do also have key figures for a short-term life." It is easy to follow up the number of employees, the number of co-workers employed full-time, part-time or on a hour basis, the number of co-workers on sick leave etc. Most respondents share the opinion that they have designed the economic indicators by themselves, but today they do it together with a consulting firm. The focus is usually on "the average costs for a trip." In this way, the managers learn how well their logistics is working in practice and "a report can be made for at least ten, maybe twenty years backwards. It is also the case that we change some indicators when we see that the activities have changed, or so. We try to plan the activities forward on the basis of the most important key figures" (The Director).

The Traffic Unit Manager explains that they have a working group; each member has their own specialization, professional experiences, and they design the key indicators during common discussions. The Communication Unit Manager explains that the first key figures have been worked out many years ago, but the leading team still discusses them to choose the most relevant ones reflecting the organization's performance. They count the number of trips, permissions etc. The Permission Unit's key figures are based on their own activities. They discuss which activities are considered to be the most important ones, what is measurable, what aspects civil servants should control to improve the operations. The chief of the Permission Unit is of the opinion that "the qualitative measurement is simple, but it is difficult to put a value on the result." However, a good method to ensure the qualitative measurements is, e.g., to call up over a dozen users after their travels and ask questions dealing with their recent experience of the journey.

The IT system plays a central role in the measurements. Some aspects are measured on a daily basis, others weekly, monthly or annually. Measurements can be made on an individual or on a group level. They measure everything which is possible 
to measure, including incomes and expenses, users' travel directions, numbers of assigned permissions, additional permits during a year, received phone calls and their average time, how users perceive their trips etc. They have at their disposal an Event Database, in which they make notes about poor service, delays, accidents, injuries, incidents and drivers' carelessness. Everything like this is recorded and categorized. There are a variety of such different activities that the organization follows up on.

Some measures are very complicated, e.g. the Manager of Administrative Support Unit wonders how the employees' performance should be measured. Is it possible in a similar way to a switching system measuring the number of employees' calls? The Traffic Unit Manager said that they have good key figures to measure accidents on the organization's level, but they also have discussions with the employee on the individual follow-up meetings. Then, the boss always asks: "how did you contribute to achieving our operative goals during this period?" The respondent adds that the measurement on the individual level can cause a risk for sub-optimization. It can happen that the unit's staff is working successfully only for their own unit but not for the whole organization. To counteract this, they conduct seven interviews every day to check what happens with the key numbers. Then, the performance is discussed on the meetings of the leading team once a month to identify trends and how the civil servants should act:

We had a low rate when it came to the treatment of our passengers by drivers and employees. Then we got a commission from our Board of Transportation Service for the Disabled to work with this issue. We also work internally with training for drivers and special training for staff on the Travel Service Unit. Delays have also increased, and then we took our action plan and discussed how we could solve this problem. In that way, we followed the performance indicators and made efforts where it was needed. Good treatment and punctuality are very important within the whole organization (the Travel Service Manager).

Within the Administrative Support Unit, the key figures were about how much this unit was successful with coordination, economic calculations. The aim was to show what proved profitable for the whole administration. The Administrative Support Manager explained that they "measure fairly accurately, but it is not always possible to link it to individual performance or efficiency at work". For them the most important aspect is that support is delivered on time. "To measure the quality of financial statements is not simple. One could try to follow up how many mistakes are made or how many invoices are paid late. But we do not do that really systematically." The Travel Service Manager adds that the measurements are about "sticks and stick statistics". They run phone statistics: how many phone calls per minute the civil servants received; how many incoming phones they answered, how long an average conversation was etc. Regarding the qualitative measurements, the Travel Service 


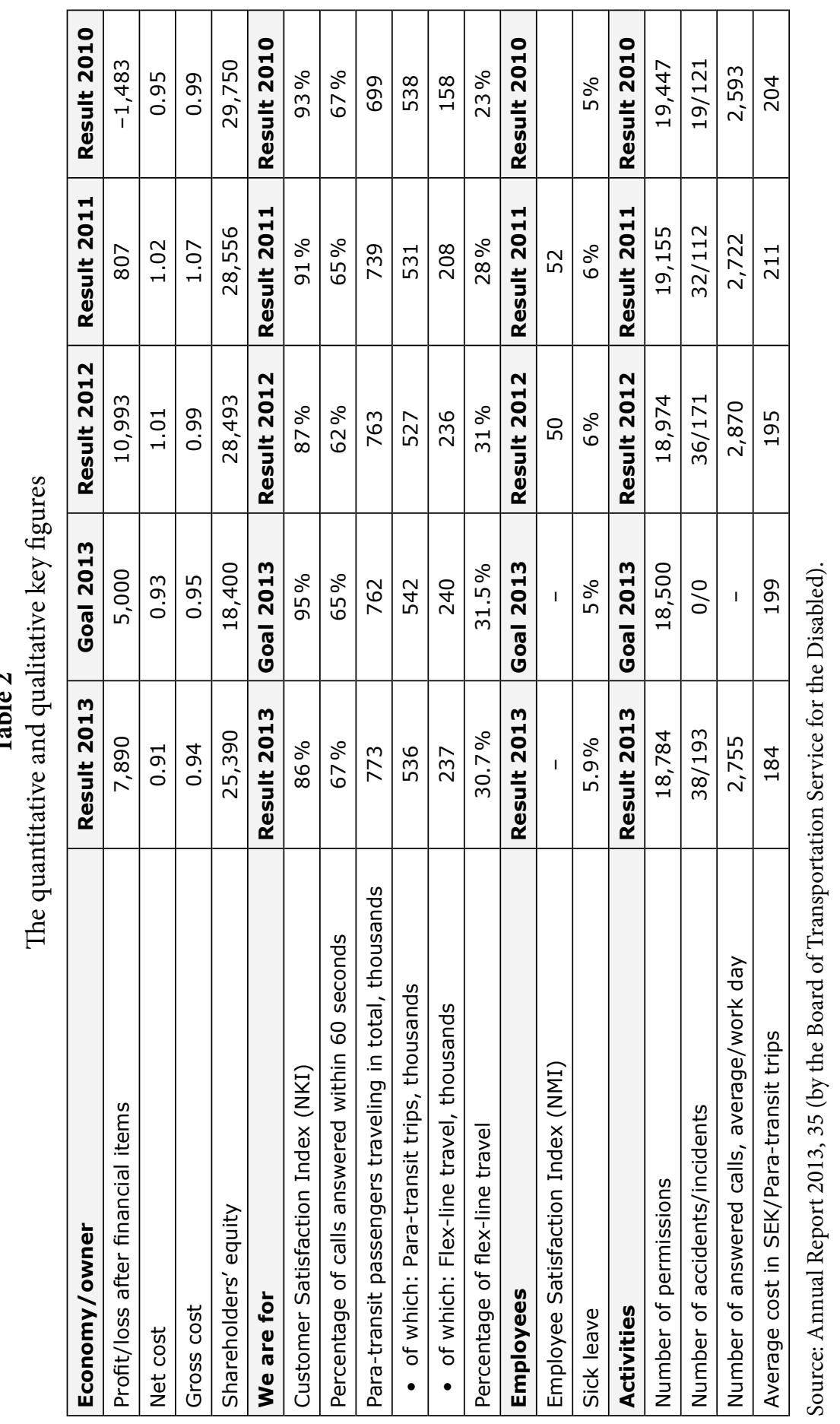


Unit receives users' opinions, comments and complaints about the services. This material is documented and investigated each month, excluding information matters. Most respondents noted that they can and should measure more achievements but they do not do that because only some key figures are the basis for the creation of the action plan or the remedial action plans when various abnormalities of the activities have been identified.

The Director and the Communication Manager said that the evaluations differ from the follow-ups within the Transportation Service for the Disabled. The evaluation is about the feedback whether the organization's operative goals have been achieved in a given period. The answer to the question depends on how the measurement was conducted, analyzed and interpreted. The evaluation result is available for all, i.e. the management team, employees, traffic companies, but also for the municipal council, the Board of Transportation Service and the users. The respondents shared the opinion that the discussions about efficiency and effectiveness and the way how the result of evaluation was communicated contributed to the short-term and the long-term improvement of the organization's activities. The Director said: "We ensure results by our evaluations and by the way we follow up the activities." Moreover, they follow up the organization's activities by the indicators that already are written into the budget steering towards the goals. Two tables are presented below that show the organization's development over time with regard to the organization's performance seen from four perspectives.

Table 3

Travel development for each customer category, number of trips, thousands, 2010-2013

\begin{tabular}{|l|r|r|r|r|r|}
\hline \multicolumn{1}{|c|}{ Travel development } & $\begin{array}{r}\text { Result } \\
\mathbf{2 0 1 3}\end{array}$ & $\begin{array}{c}\text { Budget } \\
\mathbf{2 0 1 3}\end{array}$ & $\begin{array}{c}\text { Result } \\
\mathbf{2 0 1 2}\end{array}$ & $\begin{array}{r}\text { Result } \\
\mathbf{2 0 1 1}\end{array}$ & $\begin{array}{c}\text { Result } \\
\mathbf{2 0 1 0}\end{array}$ \\
\hline Para-transit trips & 536 & 542 & 527 & 531 & 538 \\
\hline National Para-transit trips & 3 & 3 & 4 & 3 & 3 \\
\hline Flex travels, flex services-travellers & 237 & 240 & 236 & 208 & 158 \\
\hline Para-transit Travellers & $\mathbf{7 7 6}$ & $\mathbf{7 8 5}$ & $\mathbf{7 6 7}$ & $\mathbf{7 4 2}$ & $\mathbf{6 9 9}$ \\
\hline Flex travels & 53 & 55 & 57 & 65 & 66 \\
\hline Transportation Service GBG & $\mathbf{8 2 9}$ & $\mathbf{8 4 0}$ & $\mathbf{8 2 4}$ & $\mathbf{8 0 7}$ & $\mathbf{7 6 5}$ \\
\hline School trip & 200 & 195 & 193 & 184 & 176 \\
\hline Other internal commission travels & 107 & 110 & 110 & 112 & 115 \\
\hline Internal customers GBG & $\mathbf{3 0 7}$ & $\mathbf{3 0 5}$ & $\mathbf{3 0 3}$ & $\mathbf{2 9 6}$ & $\mathbf{2 9 1}$ \\
\hline External commission trips & 161 & 159 & 165 & 164 & 159 \\
\hline External customers & $\mathbf{1 6 1}$ & $\mathbf{1 5 9}$ & $\mathbf{1 6 5}$ & $\mathbf{1 6 4}$ & $\mathbf{1 5 9}$ \\
\hline Total & $\mathbf{1 , 2 9 7}$ & $\mathbf{1 , 3 0 4}$ & $\mathbf{1 , 2 9 2}$ & $\mathbf{1 , 2 6 7}$ & $\mathbf{1 , 2 1 5}$ \\
\hline
\end{tabular}

Source: Annual Report 2013, 25 (by the Board of Transportation Service for the Disabled). 


\subsection{The respondents about co-operation with the local politicians and other stakeholders}

The respondents frequently used the concepts of efficiency and effectiveness when talking about the quantitative and qualitative indicators for performance. The interplay between management by objectives and performance measurement, how management by objectives has contributed to the organization's increased efficiency and effectiveness was perceived as very important. All respondents emphasized that they have professional managers and professional drivers and that civil servants have always enjoyed a certain freedom of action. The last ones have been creative in finding practical operational goals that were in line with the major political objectives. Public organizations are always hierarchical, complex and steered by politicians, which public servants must respect. From the interviews it clearly appears that the local politicians and the civil servants from the Transportation Service for the Disabled have been working very closely with each other. The civil servants have an influence on the political objectives, on the operative goals and even on the decision-making in this regard. The Permission Unit Manager asserts that "politicians are interested in management by objectives and support it through their close collaboration", which enables managers to identify SMART performance indicators. Civil servants then know what to do exactly (Transportation Service Board: Annual Report 2013, 19). Evaluations and follow-ups became essential for the selection of priorities within the administration. Priorities tend to be well integrated with everyday activities. The Traffic Unit Manager was of the opinion that "discussion and administrative accountability" understood in terms of "the open-door philosophy" had a crucial importance for the organizational culture that positively influenced the organization's efficiency and effectiveness. The Director added that the exchange of ideas, fast response, feedback between managers and employees also proved important: "the management by objectives works well in the organization thanks to the organizational culture". The Traffic Unit Manager confirmed the Director's appreciation for the organizational culture, "it has essentially contributed to the increase of efficiency and effectiveness", especially focusing on customer orientation, job satisfaction and the organization's development. The Permits Unit Manager said, "I cannot imagine working without goals and follow-ups ... The performance management works great in some activities, but there are also things which work less well." They are constantly working on improvements. A few respondents have criticized the management by objectives, arguing that "there is an excessive amount of political objectives." The Director adds that political priorities can be problematic, especially those that demand extensive documentation: "the organization is documenting more than ever ... what is the purpose of this increasing documentation ... how the municipality uses the evaluation-reports ... It does take up a lot of energy." The chiefs of the Permission Unit and Traffic Unit share the opinion that the measurement can be risky. There is always a risk to measure the wrong things. 


\section{Conclusions}

The purpose of this study was to describe and explain why the Transportation Service for the Disabled succeeded and to provide some pragmatic ideas for practitioners nationally and internationally how to improve the efficiency and effectiveness of public services. We asked the following sub-questions: How were the operative goals created within the Transportation Service for the Disabled? How were the operative goals followed up? What can be learned from this case study? Regarding the first sub-question: We have investigated the practical work with the management by objectives within this public administration, and our study has shown some surprising results. The criticism directed towards management by objectives expressed by Rombach (1991) and Lundquist (1992) can be partly removed with time. Rombach (1991) argued that the lack of a common accepted definition of management by objectives and the lack of a system for adequate reward and punishment for this steering model made it inappropriate for public organizations. Lundquist (1992) instead stressed that politicians were limited in their expertise, and they were lacking practical know-how, which negatively influenced the activities of the public sector. Our study shows that the local politicians and the civil servants have learned to cooperate with each other, and this cooperation can be seen as an additional supportive steering method in relation to performance management. This cooperation and the mutual communication between the local politicians and the civil servants made it easier for the last ones to break down the major political objectives into the organizational operative goals and later on into the smaller operative target for each department of the organization. Ballantine et al. (1998) and Brorström et al. (2005) stressed that in the Swedish public sector, cooperation or united actions (in Swedish: samverkan) became a very popular steering method at the end of the 1990s and at the beginning of the 2000s, which our study also confirms.

This study also confirms Wang and Berman's observations (2000, 424), who argue that the involvement of the central authorities is important. Most respondents explained that they created the goals in a SMART way because the operative goals became Specific for each department, Measurable, Accepted by stakeholder, Realistic and Time-bound. The acronym - SMART - was perceived as the guideline how to bring about the growing efficiency and effectiveness and in consequence the growing profit. We observed that the units like Travel Service, the Permission or the Administrative Support had it much easier to create SMART quantitative indicators for performance than the qualitative ones. Moreover, from Transportation Service Board: Annual Report 2013 it appears quite clearly that such major political objectives like "Early preventive and rehabilitative interventions to children, young people and adults with substance-abuse problems will increase", "Differences in health between different socio-economic groups and Gothenburg parts should be reduced", "School should increase children's and students' opportunities to seek and develop skills, abilities, and values" or "School must increasingly compensate 
for pupils' different conditions on both a student level and between schools" (see Table 1 in this article) proved very challenging for the civil servants to turn into the operative goals for this public administration. Thus, we share the criticism from the previous research in this regard. Our study has also shown that the measurement of social benefit and the growing quality of the provided service seems to be "an impossible mission". The study shows that the performance measurement was not always derived from the major political objectives. The most important driving force behind the shaping of operative goals was the internal cooperation among colleagues and the external cooperation with the local politicians, the users of transportation service and other stakeholders. Thus, the active participation of many stakeholders in the creation of goals seems to be a key concept and is in line with Bovaird and Löffler's understanding of "good local governance" (2002, 17ff). It also suggests that the organizational culture is working positively for the performance.

Regarding the second sub-question: How were the operative goals followed up? The presented literature on management by objectives emphasized that follow-ups and evaluations are very important for the organization's learning and development. Isgrove and Patel (1993), Otley (1999), Ferreira and Otley (2005), Berman and Wang (2000) and Broadbent and Laughlin (2009) share the opinion that it is very difficult to develop good indicators to measure the organization's effectiveness. According to them, it is important to know how the management by objectives was formed and which key figures constituted the control system for the whole organization's performance and to compare the performance results over time. Key figures should reflect what is really measured and how it is done. MacPherson (2007) argued that a balance between the traditional economic measures of a quantitative character and the qualitative measurement of social benefit should be preserved because when behaviours change, key figures have to be adapted to those changes. Thus, knowledge about intended and non-intended effects of performance management in a given period should be collected and relate to both the short-term and the long-term effects. Having this in mind, our study showed some surprising results again. The first impression was that the Transportation Service for the Disabled lived up to the research presented in this article, particularly to Broadbent and Laughlin's $(2009,290)$ model of performance-management system (see Figure 1 in this paper). The organization's operative goals seemed to be anchored within the political objectives (see Table 1 in this paper); however, not all goals. The key indicators were designed in the cooperation with the consulting firm, but also through discussions between the organization's leading group and co-workers but also in the cooperation between civil servants and politicians. The civil servants measured both the performance and the processes through the questionnaires and interviews with the organization's staff and the users of services. The clerks had short telephone calls with the users about their last experiences of transportation services. Because the measurement within the Units of Travel Service, Permission and Administrative Support based on quantitative data worked pretty well thus far, follow-ups were informative 
enough for tracking the occurring changes over time. The civil servants could take advantages of such performance measurement, but the indicators of social benefit and quality of services proved problematic. The requirement that the civil servants ought to continuously report about all organization activities and processes was time-consuming and occurred at the expense of the main activity; therefore the Transportation Service for the Disabled had to hire the consulting company to support the civil servants in reporting. In line with Halachmi $(2005,5)$ who asserts that Kaplan and Norton's balanced scorecard (BSC) seeks to overcome common weaknesses of performance management and tries to introduce measurement of organization's outcomes, we could observe that the consultants proposed the use of a modified version of Kaplan and Norton's BSC for performance measurement. It confirmed the structure of contents for the Färdtjänstnämndens budget of 2013 and for the Annual Report 2013 (5ff). The BSC used by the Transportation Service of the Disabled consisted of: (1) customers' perspective, (2) the organization's perspective, (3) co-workers' perspective and (4) the financial perspective. Unlike Kaplan and Norton (1996), who put their priority on the economic perspective, for the Transportation Service of the Disabled the most important one proved to be "customer in focus". In second place was the organization's perspective, while Kaplan and Norton reserve this place for the customer perspective. In third place appeared the co-worker perspective, which is more in line with Hällstén and Tengblad's (2006) theory about co-employeeship than with Kaplan and Norton' theory, where production processes were more important. Finally, in fourth place the economics perspective was mentioned, while Kaplan and Norton referred to the learning perspective. This last aspect disappeared from the agenda of Transportation Service of the Disabled, but most respondents explained that follow-ups and evaluations served for the organization's learning and development.

The striking thing was that the Transportation Service for the Disabled used additional steering models other than only management by objectives, which in Sweden is a normal situation. Although the study showed that the Transportation Service for the Disabled used a plethora of key indicators, the deeper analysis of the tables from Transportation Service Board: Annual Report 2013 gives the impression that the issue of goals and means reflects a process. Most measurements were focused on the organization's activities and assigned money to them not based on the achievement of goals. Thus, the typical process-based control was used, which is described by Brorström, et al. $(2005,367)$. The study therefore demonstrated that the Transportation Service for the Disabled did not only follow the model of management by objectives, but this administration took inspiration from additional steering models like internal and external cooperation and BSC, which became "a fashion" that was followed. Such a mix of steering models occurs frequently in public organizations and depends on the organization's general conditions. Thus, the Transportation Service for the Disabled is no exception in this regard. The clerks rather measure what can be measured, e.g. different forms of travel, number 
of granted permits, number of vehicles and financial calculations etc. They have relatively good knowledge about the binding state regulations, policy governing the transportation services.

Our third question was: What can we learn about the management by objectives within the Transportation Service for the Disabled? With reference to the Annual Report 2013, in which good goal fulfilment is claimed, including an economic surplus of 7,890 thousand SEK in comparison to the planned budget's goal of + 5,000 thousand SEK, we think that this result was achieved not only because of the performance management, but rather because the organization had used several steering models at the same time, which positively influenced the organizational culture as a consequence. The civil servants were actively looking for effective steering and controlling models. The hired consulting company essentially contributed to the spread of organizational standards, e.g. the current popular steering and controlling models. Some respondents repeatedly mentioned the following concepts: management by objectives, performance management, performance measurement and follow-ups, client-performer model, internal and external cooperation, balanced scorecard, public procurement and process control.

Many advocate for the leading team of Transportation Service for the Disabled to take into account the criticism directed towards management by objectives coming from research and from everyday practice during the last two decades. They were also responsive to the new theoretical control models that could contribute to keeping the budget in balance, to having some savings and to developing the organization. This mix of performance management systems (PMS) probably enriched the management by objectives, but even PMS focused mainly on the measurement of output, not outcomes. There is still a lack of empirical evidences that could confirm the growing social benefit and the increase of quality of provided services. The fact that the public servants and service providers became more professional because they participated in various training programs, where they could develop their skills, of course contributed to some positive effects for the organization and for the users. However, we observed that the increasing professionalism did not reduce the clients' complaints over provided services. To the contrary, we have the impression that the organization's profit took place partly at the expense of employees because sick leave of 60 days increased significantly, which suggests that not all employees experienced well-being at their workplace. Thus, the modified version of BSC that introduced the co-worker perspective made sense; this perspective showed very clearly that the organization had to undertake some remedial measures to counteract this development.

Summing up, our study showed that the functional mix of performancemanagement systems had positive effects on the new organizational culture within the Transportation Service for the Disabled, based on common values, frequent meetings, exchange of information and discussions among most stakeholders. This 
culture probably has created opportunities for the employees' active participation in decision-making, an open working climate and brought about the new organizational behaviours supporting the achievement of economic goals (output), but not necessarily similarly supportive of social benefits (outcomes), even if the number of services for the Disabled was growing, e.g. growing travel flexibility and the improvement in working environment but still too little has been done. Our observation is again in line with previous research and shows that neither the management by objectives nor the functional mix of performance-management systems seems to be sufficient steering models for the public sector. Thus, Kaplan and Norton's argument; "If you can't measure it, you can't manage it" is still valid. However, independently of our criticism, we think that the Swedish model of local governance might still be interesting for other countries because this case can be seen as a SMART solution for increasing efficiency. We believe that hard work with organizational culture, its basic assumption, common values and norms for behaviours may also contribute to workers' well-being and to growing effectiveness. Figure 1 presented the new element of the PMS model reporting about implicit financial transfers and accountability in a relationship between provider and receiver. However, the PMS model is not sensitive enough to the relationship between provider and receiver. The issue of relationship concerns not only the relations between service provider and receiver but also the relations among the organization's staff, which can be seen as an essential part of organizational culture. We think that the organization's culture proved to be an important steering factor supporting the organization's vision, goals and strategy to reach them but also making a stronger organizational structure, its division of labour into working positions and needed responsibilities towards colleagues, service receivers and other stakeholders. The Swedish case can be seen as a good practice, even if it still deserves improvement. Of course, the case study never allows any generalization. Hence, the study results deserve further research to gain more knowledge, if it is possible to find more public organizations that have succeeded because they used the PMS model and a friendly organizational culture.

\section{References}

Almqvist, Roland. 2006. New Public Management: Om konkurensutsättning, kontrakt och kontroll. Malmö: Liber.

Ballantine, Joan, Stan Brignall and Sven Modell. 1998. "Performance Measurement and Management in Public Health Services: A Comparison of U.K. and Swedish Practice." Management Accounting Research 9, 71-94.

Bovaird, Tony and Elke Löffler. 2002. "Moving from Excellence Models of Local Service Delivery to Benchmarking 'Good Local Governance." International Review of Administrative Sciences 68, 9-24. 
Boyne, George and Julian Gould-Williams. 2003. "Planning and Performance in Public Organizations." Public Management Review 5(1), 115-132.

Broadbent, Jane and Richard Laughlin. 2009. "Performance Management Systems: A Conceptual Model.” Management Accounting Research 20, 283-295.

Brorström, Björn, Anders Haglund and Rolf Solli. 2005. Förvaltningsekonomi. Lund: Studentlitteratur.

Carlin, Tyrone M. 2004. "Output-Based Management and the Management of Performance: Insights from the Victorian Experience." Management Accounting Research 15, 267-283.

Denters, Bas and Lawrence E. Rose (eds). 2005. Comparing Local Governance: Trends and Developments. New York, Basingstoke: Palgrave Macmillan.

Drucker, Peter F. 1955. The Practice of Management. London: Heinemann.

Ehrenberg, Rudolph H. and Ronald J. Stupak. 1994. "Total Quality Management: Its Relationship to Administrative Theory and Organizational Behavior in the Public Sector." Public Administration Quarterly 18(1), 75-98.

Evans, James R. 2004. "An Exploratory Study of Performance Measurement Systems and Relationships with Performance Results." Journal of Operations Management 22, 219-232.

Ferreira, Aldónio and David Otley. 2009. "The Design and Use of Performance Management Systems: An Extended Framework for Analysis." Management Accounting Research 20, 263-282.

Färdtjänstnämndens budget of 2013 (Transportation Service Board's Budget by 2013). Available at http://www5.goteborg.se/prod/Intraservice/Namndhandlingar/SamrumPortal.nsf/5AC9F2837E8D4BC4C1257A9F00252278/\$File/ Bilaga_Forslag_till_budget_2013.pdf?OpenElement (last accessed 14 September 2015).

Färdtjänstnämndens uppföljningsrapporter. 2013 (Transportation service followup reports of the Board of 2013). Available at http://www5.goteborg.se/prod/ Intraservice/Namndhandlingar/SamrumPortal.nsf/F24B88FFD1383341C 1257B5000260DFA/\$File/Uppfoljningsrapport_1_2013.pdf?OpenElement (last accessed 14 September 2015).

Färdtjänstnämnden: Årsrapport. 2013 (Transportation Service Board: Annual Report 2013). Available at http://www5.goteborg.se/prod/Intraservice/Namndhandlingar/SamrumPortal.nsf/D606144B645C4416C1257C71004F8FF6/ \$File/Arsrapport\%202013.pdf?OpenElement (last accessed 14 September 2015). 
Goddard, Andrew. 2010. "Contemporary Public Sector Accounting Research: An International Comparison of Journal Papers." The British Accounting Review 42, 75-87.

Gray, Andrew and Bill Jenkins. 1995. "From Public Administration to Public Management; Reassessing a Revolution." Public Administration 7(3), 75-99.

Grönlund, Anders and Sven Modell. 2006. Effektivitet och styrning i statliga myndigheter [Efficiency and control of State authorities]. Lund: Studentlitteratur.

Halachmi, Arie. 2005. "Performance Measurement is only One Way of Managing Performance." International Journal of Productivity and Performance Management 54(7), 502-516. Available at http://dx.doi.org/10.1108/17410400510622197.

Hyndman, Noel and Ron Eden. 2000. "A Study of the Coordination of Mission, Objectives and Targets in UK Executive Agencies." Management Accounting Research 11, 175-191.

Hyndman, Noel and Ron Eden. 2001. "Rational Management, Performance Targets and Executive Agencies: Views from Agency Chief Executives in Northern Ireland." Public Administration 79(3), 579-598.

Hällstén, Freddy and Stefan Tengblad (ed.). 2006. Medarbetarskap i praktiken. Lund: Studentlitteratur.

Isgrove, Robert and Anoop Patel. 1993. "Quality Progress in UK Social Services Departments: An Exploratory Study." International Journal of Public Sector Management 6(6), 55-66.

Johansson, Bertil and Britt Johansson. 1994. Att styra eller inte styra. En kritisk granskning av den svenska grundskolans förändrade styrning med inriktning mot planeringsdokument. Lund: Pedagogiska Institutionen.

Johanson, Ulf and Matti. Skoog. 2007. Verksamhetsstyrning, för förändring, förbättring och utveckling. Malmö: Liber.

Kaplan, Robert S. and David P. Norton. 1996. The Balanced Scorecard: Translating Strategy into Action. Boston: Harvard Business Review Press.

Kommunallagen (KL) (Local Government Act) 1991:900.

Kravchuk, Robert S. and Roland W. Schack. 1996. "Designing Effective Performance Measurement Systems under the Government Performance and Results Act of 1993." Public Administration Review 56(4), 348-358.

Lag om färdtjänsten (SFS 1997:736) [Act on Transportation for the Disabled].

Lag om kollektivtrafik (SFS 2010:1065) [Act on Public Transport].

Lag om riksfärdtjänsten (SFS 1997:735) [Act on National Transportation for the Disabled]. 
Lapsley, Irvine. 1999. "Accounting and the New Public Management: Instruments of Substantive Efficiency or a Rationalizing Modernity?" Financial Accountability and Management 15(3-4), 201-207.

Lemieux-Charles, Louise, Wendy McGuire, François Champagne, Jan Barnsley, Donald Cole and Claude Sicotte. 2003. "The Use of Multilevel Performance Indicators in Managing Performance in Health Care Organizations." Management Decision 41(8), 760-770.

Lindgren, Lena. 2008. Utvärderingsmonstret. Kvalitets- och resultatmätning i den offentliga sektorn. Lund: Studentlitteratur.

Lundquist, Lennart. 1992. Förvaltning, Stat, och samhälle. Lund: Studentlitteratur.

MacPherson, Malcolm. 2001. "Performance Measurement in Not-for-Profit and Public Sector Organization." Measuring Business Excellence 5(2), 13-17.

Modell, Sven. 2004. "Performance Measurement Myths in the Public Sector: A Research Note." Financial Accountability \& Management 20(1), 39-55.

Otley, David. 1999. "Performance Management: A Framework for Management Control Systems Research." Management Accounting Research 10, 363-382.

Ouchi, William G. 1977. “The Relationship between Organizational Structure and Organizational Control.” Administrative Science Quarterly 22, 95-112.

Peng, Tzu-Ju, Stephen Piken and Göran Roos. 2007. "Intellectual Capital and Performance Indicators: Taiwanese Healthcare Sector." Journal of Intellectual Capital 8(3), 538-556.

Politiska inriktningsmål, 2013. [Policy orientation, 2013].

Rombach, Björn. 1991. Det går inte att styra med mål. Lund: Studentlitteratur.

Shah, Anwar and Sana Shah. 2006. "The New Vision of Local Governance and the Evolving Roles of Local Governments.” In Anwar Shah (ed.). Local Governance in Developing Countries: Public Sector Governance and Accountability Series. Washington DC: The World Bank, 1-46.

Smith, Peter. 1993. "Outcome-Related Performance Indicators and Organizational Control in the Public Sector." British Journal of Management 4(3), 135-151.

Smith, Peter. 1995. "Performance Indicators and Outcome in the Public Sector." Public Money and Management 15(4), 13-16.

Stevens, Philip, Lucy Stokes and Mary O’Mahony. 2006. “Metrics, Targets and Performance." National Institute Economic Review 197(1), 80-92.

Så här styrs staden. 2008. (In this way, the city is steered, 2008). Available at http:// www4.goteborg.se/prod/sk/ledarsida/dalis2.nsf/vyFilArkiv/sa_styrs_staden. pdf/\$file/sa_styrs_staden.pdf(last accessed 13 April 2014). 
Trafikförsörjnings program 2013-2015 för färdtjänst och riksfärdtjänst. Göteborgs Stad. [Traffic Maintenance Programs for Special Transportation and National Mobility, 2013-2015. The Municipality of Gothenburg].

Vakkuri, Jarmo and Pentti Meklin. 2003. "The Impact of Culture on the Use of Performance Measurement Information in the University Setting." Management Decision 41(8), 751-759.

Verbeeten, Frank H. M. 2008. "Performance Management Practices in Public Sector Organizations: Impact on Performance." Accounting, Auditing \& Accountability Journal 21(3), 427-454.

Walle van de, Steven. 2008. "Comparing the Performance of the National Public Sectors: Conceptual Problems." International Journal of Productivity and Performance Management 57(4), 329-338.

Wang, XiaoHu and Evan Berman. 2001. "Hypotheses about Performance Measurement in Counties: Findings from a Survey." Journal of Public Administration Research and Theory 11(3), 403-428.

Yrkande (S, V, MP) Policy inriktningsmål, 2013 [Claim (S, V, MP) Policy orientation, 2013].

Zineldin, Mosad. 2006. “The Quality of Health Care and Patient Satisfaction: An Exploratory Investigation of the 5Qs Model at Some Egyptian and Jordanian Medical Clinics." International Journal of Health Care Quality Assurance 19(1), 60-92. 